\title{
MAF Family Gene
}

National Cancer Institute

\section{Source}

National Cancer Institute. MAF Family Gene. NCI Thesaurus. Code C18545.

Maf family proteins possess a highly conserved basic leucine zipper (bZip) domain and are subdivided into large and small Maf proteins. The Maf family proteins appear to regulate cell differentiation processes and also cellular functions as partner molecules of CNC family proteins. 